\title{
PROGNOSTIC VALUE OF hMLH1 AND hMSH2 IMMUNOHISTOCHEMICAL EXPRESSION IN NON-SMALL CELL LUNG CANCER. A TISSUE MICROARRAY STUDY
}

\author{
Jozef Skarda ${ }^{a *}$, Eduard Fridman ${ }^{\mathrm{b}}$, Pavlina Plevova ${ }^{\mathrm{a}}$, Marian Hajduch ${ }^{\mathrm{c}}$, Lenka Radova ${ }^{\mathrm{c}}$, \\ Efrat Ofek $^{\mathrm{b}}$, Jury Kopolovic ${ }^{\mathrm{b}}$, Vitezslav Kolek ${ }^{\mathrm{d}}$, Zdenek Kolar ${ }^{\mathrm{a}}$
}

\begin{abstract}
a Department of Pathology, Faculty of Medicine and Dentistry, Palacky University, Olomouc, Czech Republic
${ }^{b}$ Laboratory of Experimental Medicine, Departments of Pediatrics and Oncology, Faculty of Medicine and Dentistry, Palacky University, Olomouc, Czech Republic

c Department of Pathology, The Chaim Sheba Medical Center and Sackler School of Medicine, Tel Aviv University, Tel-Aviv, Israel

d Department of Tuberculosis and Respiratory Diseases Faculty of Medicine and Dentistry, Palacky University, Olomouc e-mail:jojos@email.cz
\end{abstract}

Received: May 5, 2006; Accepted: June 16, 2006

Key words: Non-small cell lung cancer/Prognosis/Mismatch repair/hMLH1/hMSH2/Tissue microarray

Background: $h M L H 1$ and $h M S H 2$ genes are both known to play a role in DNA mismatch repair. Nonetheless, the clinical significance of $h M L H 1$ and $h M S H 2$ protein expression in lung cancers remains unclear.

Aim: The aim of this study was to investigate the immunohistochemical expression of $h M L H 1$ and $h M S H 2$ proteins in tumor specimens from 179 non-small cell lung cancer (NSCLC) patients using a tissue microarray technique and to correlate these results with other clinicopathological variables, including the disease specific and overall survivals.

Method: hMLH1 and hMSH2 protein expression was evaluated by immunohistochemistry using monoclonal antibodies G168-728 for hMLH1 and FE11 for hMSH2 protein expression analysis. The Pearson $\chi^{2}$ test was used to compare the hMLH1 and hMSH2 alterations among the cases and between various clinical and laboratory variables. $P<$ or $=0.05$ was considered statistically significant.

Results: Alteration of $h M L H 1$ and $h M S H 2$ protein expression was observed in $10 \%$ of patients. No significant correlation was found between the protein expression and patient age, smoking status, tumor histology or disease stage and disease free and overall survival.

Conclusions: Alterations in the expression of hMLH1 and hMSH2 proteins did not have any prognostic value in stage III. NSCLC patients.

\section{INTRODUCTION}

Lung cancer has become the leading cause of cancer death in many industrialized countries. Molecular biological studies have shown that cancer cells carry multiple genetic and epigenetic alterations, which seem to indicate the involvement of tumor suppressor genes and dominant oncogene activation pathways during the process of carcinogenesis and tumor progression ${ }^{20,25}$. Alterations of genes involved in DNA repair, may explain the susceptibility of non-risk populations, for instance, to lung cancer, non-smoking women, $h M L H 1$ and $h M S H 2$ genes are both known to play a role in DNA mismatch repair ${ }^{1}$. Their inactivation by promoter hypermethylation has been reported to be associated with human cancers ${ }^{5,7,12,15,24}$. Herman et al. ${ }^{12}$ have suggested that DNA methylation associated with transcriptional silencing of $h M L H 1$ is the underlying cause of mismatch repair defects in most sporadic colorectal cancers. Xinarianos et al. ${ }^{29}$ have shown that $58.6 \% / 57.8 \%$ of lung cancer tumor specimens expressed reduced tumor hMLH1/hMSH2 levels, respectively ${ }^{29}$.

Nonetheless, the clinical significance of $h M L H 1$ and $h M S H 2$ protein expression in lung cancers remains unclear. Recently, Brooks et al. ${ }^{2}$ reported that low protein expression of $\mathrm{hMSH} 2$ in nodal positive cancers was associated with poor response to therapy and earlier cancer deaths in patients with stage III non-small cell lung cancer (NSCLC).

Our study is to complement published data on the role of $h M L H 1$ and $h M S H 2$ protein expression in NSCLC and to demonstrate its importance for prognosing the patients's outcome.

\section{MATERIALS AND METHODS}

Study population and tumor samples. 179 consecutive patients diagnosed with early stage and operable NSCLC between years 1996 and 2001 were enrolled in this study. Out of these 58 were adenocarcinomas, 106 were sqamous cell carcinomas and 15 large cell carcinomas. The patient population consisted of 150 males and 29 females. The distribution of patients within stages, at the time of diagnosis, was the following: 104 patients were in stage 

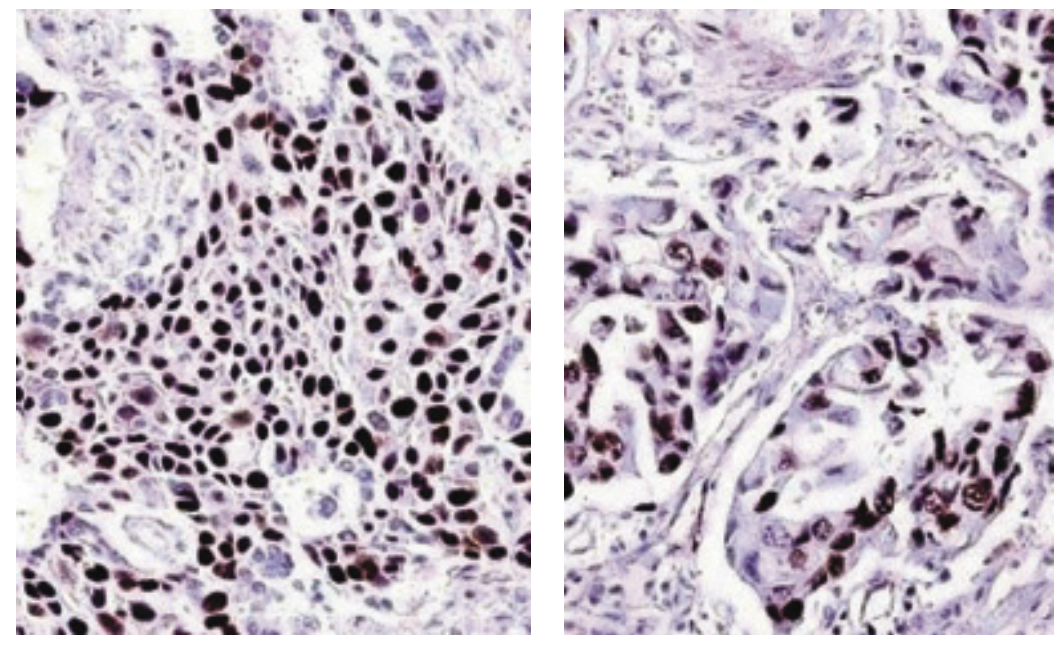

Fig. 1. Representative figures of positive immunohistochemical analysis of hMLH1 $(A)$ and hMSH2 $(B)$ protein expression in paraffin sections of non-small cell lung tumor

IIIa, 20 patients were in stage IIIb, 34 patients in stage I and II, and 21 patients in stage IV. 47 patients had received neoadjuvant chemotherapy based on carboplatin and taxol. All patients that had received neoadjuvant chemotherapy were stage IIIa patients. 21 patients had received adjuvant chemotherapy based on carboplatine or cis-platin in combination with gemcitabine or vinorelbine. The follow-up was available for all patients. This study was censored as October 2002. Overall survival was calculated from date of diagnosis to the date of death or the last follow-up. Disease specific survival (DSS) was calculated from the date of diagnosis to the date of either lung cancer associated death or the last follow-up. The mean follow-up period for all patients was 32 months (range: 0.5-78 months). During the observation period, $40 \%$ (71) patients died from lung cancer with DSS of 17 months (range: 0.5-44 months).

Tissue microarray construction. Tumor tissue microarrays were constructed using 179 formalin-fixed primary lung cancers, as stated above. The tissue area for sampling was selected based on visual alignment with the corresponding H\&E-stained section on a slide. Between three and five tissue cores ( $2 \mathrm{~mm}$ in diameter, $3-4 \mathrm{~mm}$ in height) taken from a donor tumor block were placed into a recipient paraffin block with a manual tissue microarrayer (Beecher Instruments, Sun Prairie, WI). A core of normal tissue was also punched from each case in parallel. Four $\mu \mathrm{m}$ sections of the microarray block were used for immunohistochemical analysis.

Analysis of protein expression by immunohistochemistry. Tumor microarray paraffin blocks were cut into $4 \mu \mathrm{m}$ sections and processed using the previously described methodology ${ }^{26}$. hMLH1 and hMSH2 protein expression was evaluated by immunohistochemistry using monoclonal antibodies G168-728 (1:250; PharMingen, San Diego, CA) for hMLH1 and FE11 (1:50; Oncogene Science, Cambridge, MA) for hMSH2. Since the normal staining pattern for hMLH1 and hMSH2 is nuclear, the absence of nuclear staining in tumor cells along with posi- tive staining in infiltrating lymphocytes was considered negative.

Statistical analyses. The Pearson $\chi^{2}$ test was used to compare the hMLH1 and hMSH2 alterations among the cases and between various clinical and laboratory variables. The difference in age distribution between patients with and without the alteration was analyzed by the independent sample $t$ test. Type III censoring was done on subjects who were still alive at the end of the study. Censoring for the disease-specific survival analysis was performed on subjects who were not lost in the follow-up. Survival curves were calculated by the Kaplan-Meier method, and comparison was done by the log-rank test. $P<$ or $=0.05$ was considered statistically significant.

\section{RESULTS AND DISCUSSION}

Alterations of hMLH/hMSH2 protein expression and its correlations with clinical and laboratory variables in lung cancer patients: Immunohistochemical staining for hMSH2 and hMLH1 protein expression was performed on 179 tumor samples, where only nuclear staining of tumor cells was considered positive. Ninety percent of tumor specimens showed moderate to strong staining for both proteins (Fig. 1A and 1B). However, 10 percent of tumors showed complete absence of nuclear staining. There was no significant correlation between the protein expression and patient age $P=0.35$, smoking status $P=0.55$, tumor histology $P=0.65$ or disease stage $P=0.75$. No differences have been observed in the percentages of positive patients/ negative patients with or without neoadjuvant chemotherapy. $P<$ or $=0.75, P<$ or $=0.65$.

Correlation of hMLH1 and hMSH2 alterations with overall and disease free survival of the stage III non-small cell lung cancer patients, with regards to neoadjuvant chemotherapy. The relationship between survival and the alteration of $h M L H 1$ and $h M S H 2$ was further analyzed (Fig. 2).

In this study, we investigated the significance of the 
Overall survival of patients expressing MLH1 and MSH2 with regards to neoadjuv. chtp., stage III o complete + censored

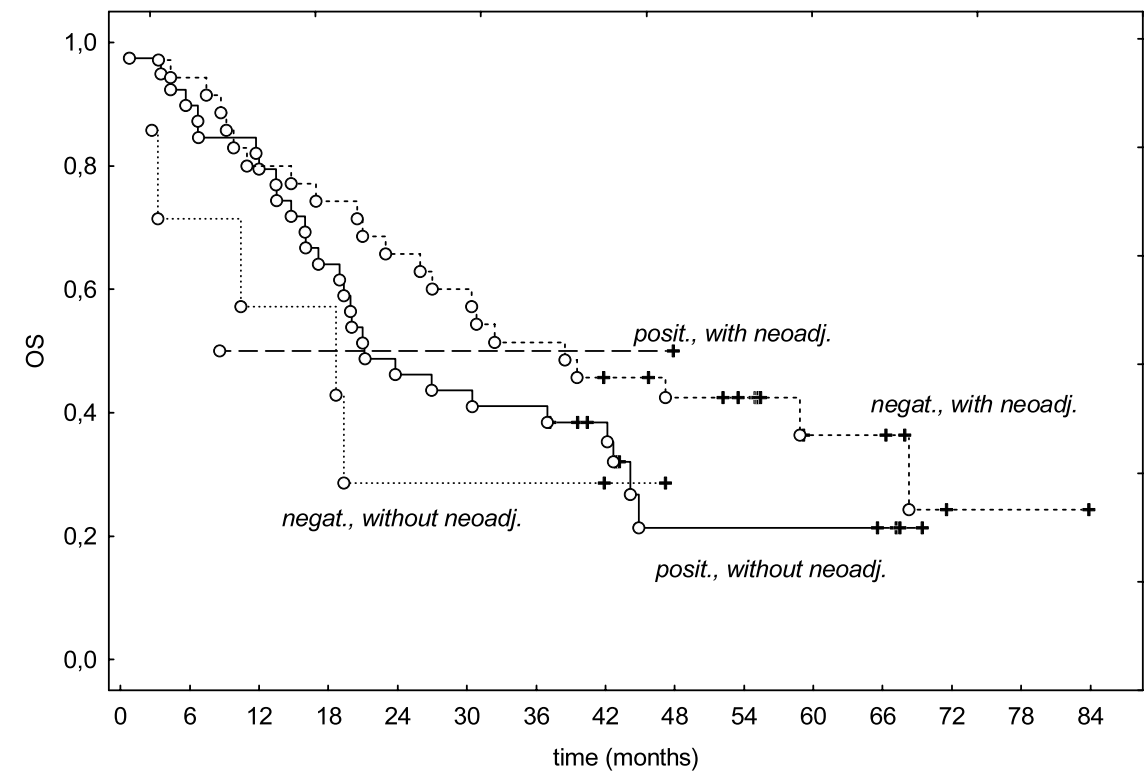

Fig. 2. Correlation of hMLH1 and hMSH2 alterations with the prognosis of non-small cell lung cancer stage III. patients. The relationship between overall survival and the alteration of hMLH1 and hMSH2 was analyzed. No significant differences were observed in overall survival of hMLH1 and hMSH2 positive / negative patients regardless of neoadjuvant chemotherapy $P=0.45$.

Disease free survival of patients expressing MLH1 and MSH2 with regards to neoadj. chemotherapy o complete + censored

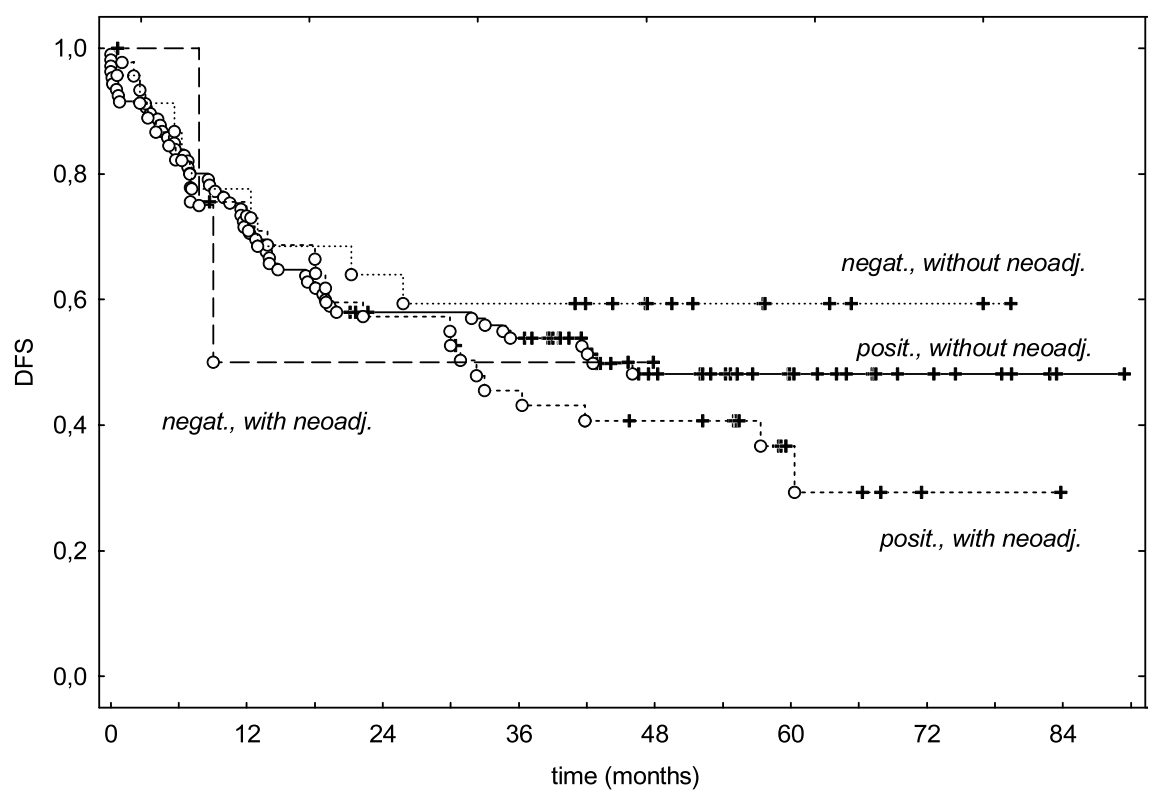

Fig. 3. Correlation of hMLH1 and hMSH2 alterations with the prognosis of non-small cell lung cancer stage III patients. The relationship between disease free survival and the alteration of hMLH1 and hMSH2 was analyzed. No significant differences were observed in disease specific survival of hMLH1 and hMSH2 positive / negative patients regardless of neoadjuvant chemotherapy $P=0.65$. 
DNA mismatch repair genes, $h M L H 1$ and $h M S H 2$ in NSCLC using immunohistochemistry. Lack of $h M L H 1$ and $h M S H 2$ protein expression was observed in $10 \%$ of tumor specimens and no significant concordance was observed between alteration in protein expression and survival of patients with regards to neoadjuvant chemotherapy.

Data on the role of the mismatch repair gene alterations in lung cancer are unclean. Xinarianos et al. ${ }^{24}$ studied 59 males and 91 females with lung cancer and showed reduced expression levels of hMLH1 and hMSH2 proteins in $53 \%$ of sqamous cell and $82 \%$ of adenocarcinoma specimens. These results do not correspond to ours except for the higher expression level of hMSH2 protein reported in the study. On the other hand, an immunohistochemical study by Aubry et al. ${ }^{1}$ showed that mismatch repair proteins hMLH1, hMSH2, and hMSH6 were not inactivated in bronchioloalveolar carcinomas. In a panel of 21 small cell lung cancer cell lines using the MSP assay, Hansen et al. showed that low hMLH1 protein expression was not linked to promoter methylation ${ }^{11}$. The discrepancies between the various studies may be due to differences in clinical and laboratory parameters. Moreover, the methylation regions examined and sensitivities of the applied methodologies may vary from study to study. It is also possible that geographic and/or ethnic factors may account for frequent $h M L H 1$ and $h M S H 2$ alterations in NSCLC patients, as was reported for activating EGFR1 mutations $^{22}$.

Some authors suggested a relationship between the expression of hMLH1 and hMSH2 proteins and cancer drug resistance or response ${ }^{2,13,17}$. Strathdee et al. ${ }^{22}$ investigated the role of $h M L H 1$ gene methylation in drug resistance using ovarian cancer cell lines and suggested that methylation of the $h M L H 1$ promoter may be a common mechanism for cisplatin based resistance in ovarian cancers $^{22}$. In addition, Mackay et al. reported that reduction of hMLH1 protein expression in breast tumor samples after chemotherapy was strongly associated with poor disease-free survival ${ }^{17}$. To the best of our knowledge, this study is the first to investigate the relationship between the status of $h M L H 1$ or $h M S H 2$ expression in primary NSCLCs. and survival of NSCLC patients with regards to neoadjuvant therapy.

The association between DNA inactivation of mismatch repair gene alterations and genetic instabilility has been described in several cancers. Loss of $h M L H I$ gene expression has been proven to be the main cause of microsatellite instability in colorectal cancers ${ }^{7,24}$. It has also been shown that selective defects in mismatch repair genes may cause genomic instability and activate malignant transformation as well as progression of gastric cancer, renal cell carcinoma, and endometrial carcinoma ${ }^{5,10,15}$. Highly significant correlation between gene methylation and negative protein expression in $h M L H 1$ and $h M S H 2$ suggests that promoter hypermethylation is the predominant mechanism in seeming these two mismatch repair genes in NSCLC ${ }^{24,25}$ and thus, genetic instability may contribute to poor prognosis in human cancers.
It seems that DNA hypermethylated tumors, both unstable and stable, have distinct clinical features. However, further analyses particularly in lung cancers are required to better understand the clinical significance.

\section{ACKNOWLEDGEMENTS}

This work has been supported in parts from the Internal Grant Agency of the Ministry of Health (IGA MZ ČR NR/ 8425-3/2005) and Ministry of School and Education of the Czech Republic (MSM6198959216)

\section{REFERENCES}

1. Aubry MC, Halling KC, Myers JL, Tazelaar HD, Yang P, Thibodeau SN. DNA mismatch repair genes hMLH1, hMSH2, and hMSH6 are not inactivated in bronchioloalveolar carcinomas of the lung. Cancer 2001; 92:2898-901.

2. Brooks KR, To K, Joshi MB, Conlon DH, Herndon JE, D'Amico TA, Harpole DH Jr. (2003) Measurement of chemoresistance markers in patients with stage III non-small cell lung cancer: a novel approach for patient selection. Ann Thorac Surg 76:187-93.

3. Chang JW, Chen YC, Chen CY, Chen JT, Chen SK, Wang YC. Correlation of genetic instability with mismatch repair protein expression and p53 mutations in non-small cell lung cancer. Clin Cancer Res 2000; 6:1639-46.

4. Chiu YL, Yu TS, Wong TW. Time trends of female lung cancer in Hong Kong: age, period and birth cohort analysis. Int J Cancer 2004; 111:424-30.

5. Deguchi M, Shiina H, Igawa M, Kaneuchi M, Nakajima K, Dahiya R. DNA mismatch repair genes in renal cell carcinoma. J Urol 2003; 169:2365-71.

6. de Perrot M, Licker M, Bouchardy C, Usel M, Robert J, Spiliopoulos A. Sex differences in presentation, management, and prognosis of patients with non-small cell lung carcinoma. J Thorac Cardiovasc Surg 2000; 119:21-6.

7. Deng G, Peng E, Gum J, Terdiman J, Sleisenger M, Kim YS (2002) Methylation of hMLH1 promoter correlates with the gene silencing with a region-specific manner in colorectal cancer. Br J Cancer 86:574-9.

8. Dodds L, Davis S, Polisson L. A population-based study of lung cancer incidence trends by histological type. J Natl Cancer Inst 1974; 76:21-9.

9. Esteller M, Corn PG, Baylin SB, Herman JG. A gene hypermethylation profile of human cancer. Cancer Res 2001; 61:3225-9.

10. Esteller M, Levine R, Baylin SB, Ellenson LH, Herman JG. MLH1 promoter hypermethylation is associated with microsatellite instability phenotype in sporadic endometrial carcinomas. Oncogene 1998; 16:2413-7.

11. Hansen LT, Thykjaer T, Orntoft TF, Rasmussen LJ, Keller P, SpangThomsen M, Edmonston TB, Schmutte C, Fishel R, Petersen LN. The role of mismatch repair in small-cell lung cancer cells. Eur J Cancer 2003; 39:1456-67.

12. Herman JG, Umar A, Polyak K, Graff JR, Ahuja N, Issa JP, Markowitz S, Willson JK, Hamilton SR, Kinzler KW, Kane MF, Kolodner RD, Vogelstein B, Kunkel TA, Baylin SB. Incidence and functional consequences of hMLH1 promoter hypermethylation in colorectal carcinoma. Proc Natl Acad Sci U S A 1998; 95:68705.

13. Ko YC, Wang JL, Wu CC, Huang WT, Lin MC. Lung cancer at a medical center in Southern Taiwan. Chang Gung Med J. 2005; 28(6):387-95

14. Lam WK, So SY, Yu DYC. Clinical features of bronchogenic carcinoma in Hong Kong: review of 480 patients. Cancer 1983; 52:369-76. 
15. Leung SY, Yuen ST, Chung LP, Chu KM, Chan ASY, Ho JCI hMLH1 promoter methylation and lack of hMLH1 expression in sporadic gastric carcinomas with high-frequency microsatellite instability. Cancer Res 1999; 59:159-64.

16. Lienert T, Serke M, Schonfeld N, Loddenkemper R. Lung cancer in young females. Eur Respir J 2000; 16:986-90.

17. Mackay HJ, Cameron D, Rahilly M, Mackean MJ, Paul J, Kaye SB, Brown R. Reduced MLH1 expression in breast tumors after primary chemotherapy predicts disease-free survival. J Clin Oncol 2000; 18:87-93.

18. Minami H, Yoshimura M, Miyamoto Y, Matsuoka H, Tsubota N. Lung cancer in Women. Sex-associated differences in survival of patients undergoing resection for lung cancer. Chest 2000 118:1603-9.

19. Ryberg D, Hewer A, Phillips DH, Haugen A. Different susceptibility to smoking-induced DNA damage among male and female lung cancer patients. Cancer Res 1994; 54:5801-3.
20. Rhyu MS. Molecular mechanisms underlying hereditary nonpolyposis colorectal carcinoma J Natl Cancer Inst 1996; 88:240-51.

21. Stolley PD. Lung cancer in women: five years later, situation worse. N Engl J Med 1983; 309:428-9.

22. Strathdee G, MacKean MJ, Illand M, Brown R. A role for methylation of the hMLH1 promoter in loss of hMLH1 expression and drug resistance in ovarian cancer. Oncogene 1999; 18:2335-41.

23. Takagi Y, Koo LC, Osada H, Ueda R, Kyaw K, Ma CC, Suyama M, Saji S, Takahashi T, Tominaga S, et al. Distinct mutational spectrum of the p53 gene in lung cancers from Chinese women in Hong Kong. Cancer Res 1995; 55:5354-7.

24. Xinarianos G, Liloglou T, Prime W, Maloney P, Callaghan J, Fielding P, Gosney JR, Field JK. hMLH1 and hMSH2 expression correlates with allelic imbalance on chromosome $3 p$ in non-small cell lung carcinomas. Cancer Res 2000; 60:4216-21.

25. Wang YC, Lu YP, Tseng RC, Lin RK, Chang JW, Chen JT, Shih $\mathrm{CM}$, Chen CY. Inactivation of hMLH1 and hMSH2 by promoter methylation in primary non-small cell lung tumors and matched sputum samples. J Clin Invest 2003; 111:887-95. 